
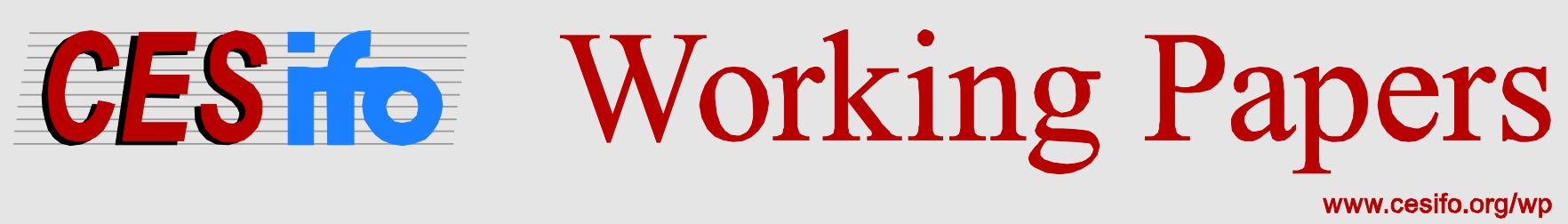

\title{
Self-Enforcing Agreements under Unequal Nationally Determined Contributions
}

\author{
Emilson C. D. Silva
}

\author{
CESIFO WORKING PAPER NO. 5708 \\ CATEGORY 9: RESOURCE AND ENVIRONMENT ECONOMICS \\ JANUARY 2016
}

An electronic version of the paper may be downloaded

- from the SSRN website: Www.SSRN.com

- from the RePEc website: Www.RePEc.org

- from the CESifo website: www.CESifo-group.org/wp 


\title{
Self-Enforcing Agreements under Unequal Nationally Determined Contributions
}

\begin{abstract}
For a large global economy with normal goods, and an unequal world income distribution, we consider the endogenous formation and stability of an international environmental agreement (IEA) under nationally determined contributions (NDCs). Nations share green R\&D efforts and enjoy R\&D spillovers if they join an IEA. Nonmembers do not enjoy R\&D spillovers. We show that the Grand Coalition is stable under NDCs if all nations are active carbon abatement and $\mathrm{R} \& \mathrm{D}$ contributors. If some nations are inactive, because they lack sufficient income to provide carbon abatement and R\&D, the stable coalition under NDCs is the coalition of all active (wealthier) nations.
\end{abstract}

JEL-codes: D740, F530, H410, Q540, Q550.

Keywords: international environmental agreements, self-enforcing, nationally determined contributions, R\&D sharing.

\author{
Emilson C. D. Silva \\ Department of Marketing, Business Economics and Law \\ Alberta School of Business \\ University of Alberta \\ Canada - Edmonton, Alberta, T6G-2R6 \\ emilson@ualberta.ca
}

January 13, 2016 


\section{Introduction}

On December 12, 2015, 195 nations reached an agreement to keep global warming well below 2 degrees Celsius, with the intention of limiting the increase in temperature to 1.5 degrees. The Paris Agreement builds on Intended Nationally Determined Contributions (INDCs) submitted by most participating nations. The INDCs vary across nations, since national circumstances differ, including national incomes and damages. The Paris Agreement will be open for ratification from April 22, 2016 and will come into effect as soon as 55 nations that account for at least 55\% of global greenhouse emissions ratify it. Some of its key components include technology and monetary transfers from rich to poor nations.

In this paper, motivated by this recent development, we examine the endogenous formation and stability of an international environmental agreement (IEA) under nationally determined contributions (NDCs). The global economy is large. The nations possess different income levels. National payoff (utility) functions are increasing and concave in consumption of private and public goods. The public good is abatement of greenhouse gas. The unequal income distribution yields variable contributions of greenhouse gas abatement and cost-reducing green R\&D in all Nash equilibria. The nations that belong to an IEA share R\&D efforts and enjoy the benefits of $R \& D$ spillovers. We demonstrate that the stable IEA is universal, involving all nations in the globe, if all nations are active abatement and R\&D contributors in all Nash equilibria. If some nations are inactive, because they do not possess enough income, the stable IEA is not universal, but it includes all active nations. The active nations are the wealthier ones. The Nash equilibria payoffs increase with the size of the IEA due to R\&D spillovers. Given this, it is always beneficial for the wealthier nations to transfer income to the poorest inactive nations to enable the latter to become active abatement and R\&D contributors.

This paper contributes to the IEA literature, which utilizes the cartel stability concept developed by d'Aspremont et al. (1983). ${ }^{1}$ In particular, this paper is closely related to the branches of the IEA literature that examine the size of the stable IEA in: (i) simultaneous non-cooperative games versus sequential ones (e.g., Stackelberg); (ii) settings with symmetric versus asymmetric

\footnotetext{
${ }^{1}$ In addition to the papers cited in the text, the following papers are good examples of closely related papers: Barret (2006, 2009), Diamantoudi and Sartzetakis (2006), Kolstad (2007), Rūbbelke and Finus (2013) and Rubio and Ulph (2006).
} 
players, (iii) settings where there are R\&D spillovers for clean (green) technologies; and (iv) in models that contain utility and cost functions.

The results obtained by the IEA literature with respect to the stable size of the IEA are generally disappointing. In general, the stable IEA contains no more than single digit nations. Carraro and Siniscalco (1991, 1993), Hoel (1992) and Barrett (1994) are seminal contributions to the IEA literature. Carraro and Siniscalco (1991) and Hoel (1992) demonstrate that the stable coalition size consists of at most three countries if the game played by the coalition and the stand-alone countries is simultaneous and non-cooperative. Barrett (1994) and Rubio and Ulph (2006), among others, consider games in which IEA signatories are Stackelberg leaders vis-à-vis non-signatories. They show that the stable IEAs may be larger in such cases, and the stable IEA may include the Grand Coalition. McGinty (2007), Biancardi and Villani (2010), Fuentes-Albero and Rubio (2010), Osmani and Tol (2010) and Pavlova and de Zeeuw (2013) consider various settings in which nations are asymmetric. They show that stable IEAs under asymmetries may be larger than stable IEAs under symmetry. El-Sayed and Rubio (2014) consider a setting where IEA signatories share R\&D efforts in a technological agreement that internalizes R\&D spillovers. Nations choose their emissions non-cooperatively after they observe the collective R\&D outputs. They demonstrate that cooperative technological agreements may yield relatively optimistic outcomes regarding emissions' reductions and the size of the stable IEA. They show that the stable IEA may contain six nations. Finally, Eichner and Pethig (2013) and Eichner and Pethig (2014) consider selfenforcing IEAs in the presence of international trade and capital mobility, respectively. Their frameworks deviate from most of the early papers in that they examine self-enforcing IEAs within general-equilibrium models. Their results are mixed. Eichner and Pethig (2013) show that if the IEA signatories are Stackelberg leaders vis-à-vis non-signatories, the size of the stable coalition can be large. However, the outcomes in terms of emission reductions are disappointing. Eichner and Pethig (2014), on the other hand, show that in general the pessimistic results regarding the small size of the stable IEA still hold; however, for a particular set of parameter values, the Grand Coalition is stable. This implies that the social optimum is implementable within the particular set of parameter values.

To the best of our knowledge, this is the first paper in the IEA literature to consider settings where the consumption goods are normal and the IEAs build on NDCs. These are the key departures from the literature. We examine non-cooperative simultaneous games played by IEA 
members and nonmembers. Our model does not possess the potential benefits associated with Stackelberg leadership, as in Barrett (1994), Rubio and Ulph (2006) and Eichner and Pethig (2013). Our players are asymmetric because they are initially endowed with different income levels. The unequal income distribution is the sole source of asymmetry. We contribute to the literature that considers self-enforcing IEAs with asymmetric players by introducing a novel source of asymmetry. Nations share R\&D efforts as in El-Sayed and Rubio (2014). However, if the IEAs are subject to NDCs, R\&D efforts are chosen non-cooperatively. Unlike El-Sayed and Rubio (2014), we assume that only IEA members enjoy R\&D spillovers. As in Eichner and Pethig (2013, 2014), our model contains utility and cost functions.

$\mathrm{R} \& \mathrm{D}$ efforts play a crucial role in our model, since they are the source of externalities that motivate nations to join the IEA. We model R\&D spillovers as in Katz (1986), even though we already assume from the outset that only IEA members enjoy R\&D spillovers and we do not consider the non-cooperative choices of the cost-sharing rule in IEAs. Katz (1986) demonstrates that the subgame perfect equilibrium for a multiple-stage game yields universal participation in an industry-wide R\&D joint venture, efficient R\&D levels and fully excludes nonmembers from enjoying R\&D spillover benefits produced by the industry-wide joint venture. In his model, firms choose the R\&D cost-sharing rule, R\&D efforts and output levels non-cooperatively. Firms also choose whether or not to join the industry-wide R\&D joint venture in a membership stage according to the cartel stability concept developed by d'Aspremont et al. (1983).

This paper is also closely related to two recent papers, Silva and Zhu (2015) and Silva and Yamaguchi (2015), which examine the role that green R\&D plays in the stability of IEAs. These papers utilize coalition-proofness, a refinement of Nash equilibrium, to select stable IEAs. They also consider symmetric players who possess quasilinear payoffs. Silva and Zhu (2015) demonstrate that in the presence of R\&D spillovers, the stable IEA may contain six nations. Silva and Yamaguchi (2015) demonstrate that in the absence of income transfers and relational attrition in R\&D collaboration, the stable IEA may be universal, including all nations in the globe. Unlike these papers, we consider settings where the consumption goods are normal, the players are asymmetric and our stability concept builds on the cartel concept developed by d'Aspremont (1983). However, since our results demonstrate that all nations are strictly better off in the stable IEA (whether the stable IEA is the Grand Coalition or a subset of the players' set which includes 
all active nations) than in any other type of coalition structure, the Nash equilibrium that yields the stable IEA is a Strong Nash equilibrium. Hence, it is also a coalition-proof Nash equilibrium.

Nordhaus (2015) has persuasively argued that free-riding is the major hurdle to the formation and stability of IEAs based on joint actions. This paper is not in disagreement with Nordhaus (2015) because we do not consider outcomes under joint actions. This paper provides full support for an alternative arrangement based on NDCs, which is currently the basis of the Paris Agreement, where free-riding is an inherent characteristic. We argue that free-riding is not necessarily an impediment for the formation and stability of a global agreement. Interestingly, the essential ingredient that leads to the formation and stability of a global agreement is a club-type characteristic, which is not internalized by the club: the R\&D produced by the IEA, based on noncooperative $R \& D$ contributions, is a club good in that it yields nonrival and nonexcludable benefits to IEA members but such benefits are perfectly nonexclubable to nonmembers.

The paper is organized as follows. Section 2 introduces the basic ingredients of the model. Section 3 shows the socially optimal allocation. Section 4 examines interior Nash equilibria under NDCs. In sections 3 and 4 we do not assume functional forms utility and cost functions. This strategy enables us to formally show and discuss the departures from internalization of externalities within IEAs in Nash equilibria under NDCs. In sections 5 and 6, we assume functional forms for utility and cost functions in order to compute payoffs and compare them. The utility function is Cobb-Douglass and the abatement cost function is quadratic. Section 5 considers settings in which all nations are active abatement and R\&D contributors. Section 6 considers a setting in which some nations are active contributors while some other nations are inactive. We carry out the stability analyses in these sections. Section 7 concludes.

\section{The Model}

Consider a world economy with $n \geq 195$ nations. Let $N=\{1, \ldots, n\}$ denote the set of nations. The nations differ with respect to their income levels. Let $w_{i}>0$ denote nation $i$ 's income, $i \in N$. We assume that the set of nations is ordered according to income levels, $w_{j} \geq w_{j+1}, j=1, \ldots, n-1$. Hence, if the inequalities hold strict, nations 1 and $n$ are respectively the richest and poorest nations in the world. We assume throughout that $2 w_{n}>2 n+1$. As we demonstrate below, this assumption guarantees that all symmetric Nash equilibria under NDCs are interior. 
Each nation contains a single consumer, which represents the aggregation of all its domestic consumers. The consumer in nation $i$ derives utility from consumption of $x_{i}$ units of a numeraire good and $Q$ units of greenhouse gas (e.g., carbon dioxide) abatement: $u^{i}=u\left(x_{i}, Q\right)$, where $u_{x}^{i} \equiv \partial u^{i} / \partial x_{i}>0, \quad u_{Q}^{i} \equiv \partial u^{i} / \partial Q>0, \quad u_{x x}^{i} \equiv \partial u_{x}^{i} / \partial x_{i}<0, \quad u_{Q Q}^{i} \equiv \partial u_{Q}^{i} / \partial Q<0, \quad u$ is concave and satisfies $\lim _{x \rightarrow 0} u_{x}^{i}=\infty$ and $\lim _{Q \rightarrow 0} u_{Q}^{i}=\infty$. We assume that $Q=\sum_{i=1}^{n} q_{i}$, where $q_{i}$ is nation $i$ 's abatement contribution.

The cost of producing $q_{i}$ units of abatement is increasing at an increasing rate in the level of abatement but it decreases with the level of cost-reducing R\&D that nation $i$ supplies, $g_{i}$. We assume that nation $i$ 's abatement cost is $c\left(q_{i}, g_{i}\right)$, where $c$ is convex, increasing at an increasing rate in $q_{i}$ and decreasing at an increasing rate in $g_{i}$. We consider settings in which international environmental agreements produce R\&D spillovers through collaboration (i.e., international joint venture) in R\&D activity. In the absence of R\&D collaboration, $g_{i}=r_{i}$, where $r_{i}$ is the amount of R\&D supplied by nation $i$. If, on the other hand, all nations are members of a global agreement to reduce carbon emissions, $g_{i}=r_{i}+\beta R_{-i}$, where $R_{-i}$ is the amount of $\mathrm{R} \& \mathrm{D}$ supplied by the rest of the world and $\beta \in[0,1]$ is the rate at which the amount of R\&D supplied by the rest of the world increases nation $i$ 's R\&D supply. ${ }^{2}$ We assume that it costs one unit of numeraire good to produce one unit of R\&D. In what follows, the total cost of producing R\&D and carbon abatement in nation $i$ is $r_{i}+c\left(q_{i}, g_{i}\right)$. Then, $x_{i}+r_{i}+c\left(q_{i}, g_{i}\right)=w_{i}$ is the budget constraint faced by nation $i$.

\footnotetext{
${ }^{2}$ Silva and Yamaguchi (2015) provide details about international green R\&D joint ventures (in carbon capture and storage technology) and discuss the pros and cons involving non-cooperative R\&D collaboration in research teams. El-Sayed and Rubio (2014) employ a similar model of R\&D spillovers. The key differences between their model and ours is that they consider a setting in which IEA members internalize R\&D spillovers and nonmembers also enjoy R\&D spillover benefits. It is straightforward to show that the stability results of this paper remain unchanged if we consider a more general model where nonmembers derive R\&D benefits provided the rate at which $R \& D$ spillovers are enjoyed by coalition members is higher than the rate at which R\&D spillovers are enjoyed by nonmembers. The analysis with nonmembers R\&D spillovers, however, is more cumbersome in terms of notation and algebra. We also conjecture that IEA members would choose to perfectly exclude nonmembers from enjoying R\&D spillovers produced by the IEA if the IEA members are able to choose the rate at which nonmembers benefit from R\&D spillovers generated by IEA members. The reasoning is identical to the one that is present in Katz (1986).
} 


\section{Socially Optimal Allocation}

As a benchmark for future comparisons, we start the analysis by considering the socially optimal allocation. We assume that the social planner is utilitarian. The planner chooses non-negative $\left\{q_{i}, r_{i}, x_{i}\right\}_{\forall i \in N}$ to maximize $\sum_{h=1}^{n} u\left(x_{h}, q_{h}+Q_{-h}\right)$ subject to the global resource constraint:

$$
\sum_{h=1}^{n}\left\{x_{h}+r_{h}+c\left(q_{h}, r_{h}+\beta R_{-h}\right)\right\}=W
$$

where $W \equiv \sum_{h=1}^{n} w_{h}$ is the global income level. Letting $\lambda \geq 0$ denote the Lagrangian multiplier associated with the global resource constraint and assuming that the solution is interior, the first order conditions yield

$$
\begin{array}{ll}
u_{x}^{i}=\lambda, & \forall i \in N, \\
\sum_{h=1}^{n} u_{Q}^{h}=\lambda c_{q}\left(q_{i}, r_{i}+\beta R_{-i}\right), & \forall i \in N, \\
-\left\{c_{r}\left(q_{i}, r_{i}+\beta R_{-i}\right)+\beta \sum_{j \neq i} c_{r}\left(q_{j}, r_{j}+\beta R_{-j}\right)\right\}=1, & \forall i \in N .
\end{array}
$$

Equation (1.2) informs us that the planner implements income transfers in order to equalize the marginal utilities of income. These conditions imply that all nations consume the same quantity of numeraire good in equilibrium. Conditions (1.3) state that the sum of the marginal utilities of the global public good must be equal to the shadow value of each nation's marginal cost of abatement. These conditions imply that the marginal costs of abatement are equalized across nations. Combining equations (1.2) and (1.3), one obtains the Samuelson conditions for provision of the global public good;

$$
\sum_{h=1}^{n} u_{Q}^{h} / u_{x}^{h}=c_{q}\left(q_{i}, r_{i}+\beta R_{-i}\right), \quad \forall i \in N .
$$

Finally, conditions (1.4) are the Samuelson-like conditions for the provision of R\&D. The sum of direct and indirect marginal cost reductions associated with provision of R\&D by nation $i$ should be equal to the marginal cost of providing $R \& D$ in nation $i$. 


\section{Nash Equilibria}

Consider now the Nash equilibria. The status-quo setting is the one where all nations stand alone in deciding their contributions of carbon abatement and cost-reducing R\&D. The global-agreement setting is the one where all nations join the international environmental agreement (IEA), but each nation decides its contribution of carbon abatement and cost-reducing R\&D taking all other nations' decisions as given. The status-quo and global-agreement settings are polar cases. We also examine Nash equilibria for partial-agreement settings in which some nations belong to the IEA while others stand alone. In all partial-agreement settings, each nation that belongs to the IEA makes its contributions taking all other nations' decisions as given. Stand-alone nations behave in a similar fashion. Contrasting the conditions that characterize the Nash equilibria below with the socially optimal conditions clearly reveals that nations do not internalize externalities in the Nash equilibria. In particular, the IEAs feature free-riding behavior in the provision of both abatement and $R \& D$.

\subsection{Status-Quo Setting}

Nation $i$ chooses non-negative $\left\{g_{i}, q_{i}\right\}$ to maximize $u\left(w_{i}-r_{i}-c\left(q_{i}, r_{i}\right), q_{i}+Q_{-i}\right)$, taking all other nations' choices as given. Assuming an interior solution for each $i \in N$, the first order conditions yield

$$
\begin{aligned}
& -c_{r}\left(q_{i}, r_{i}\right)=1, \\
& u_{Q}^{i} / u_{x}^{i}=c_{q}\left(q_{i}, r_{i}\right) .
\end{aligned}
$$

Equations (2.1) inform us that each nation chooses its level of R\&D in order to equate the marginal reduction in the cost of abatement to the marginal cost of provision. Equations (2.2) state that the amount of abatement provided by each nation is set in order to equate the nation's marginal rate of substitution between the global public good and the numeraire good to the marginal cost of abatement provision. Equations (2.1), (2.2) and the following budget constraints characterize the Nash equilibrium for the status-quo setting:

$$
x_{i}+r_{i}+c\left(q_{i}, r_{i}\right)=w_{i}, \quad \forall i \in N .
$$




\subsection{Global-Agreement Setting}

Nation $i$ chooses non-negative $\left\{g_{i}, q_{i}\right\}$ to maximize $u\left(w_{i}-r_{i}-c\left(q_{i}, r_{i}+\beta R_{-i}\right), q_{i}+Q_{-i}\right)$, taking all other nations' choices as given. Assuming an interior solution for each $i \in N$, the conditions that characterize the Nash equilibrium for the global-agreement setting are, $\forall i \in N$

$$
\begin{aligned}
& -c_{r}\left(q_{i}, r_{i}+\beta R_{-i}\right)=1, \\
& u_{Q}^{i} / u_{x}^{i}=c_{q}\left(q_{i}, r_{i}+\beta R_{-i}\right) . \\
& x_{i}+r_{i}+c\left(q_{i}, r_{i}+\beta R_{-i}\right)=w_{i} .
\end{aligned}
$$

Hence, conditions (3.1) - (3.3) differ from their counterparts, (2.1) - (2.3), in that in the global agreement each nation enjoys $R \& D$ spillovers produced by the $R \& D$ joint venture. It is important to note, however, that R\&D spillovers are not internalized. Each nation takes the R\&D contribution made by all other nations as given.

\subsection{Partial-Agreement Settings}

In any partial-agreement setting, there are nations that form an IEA and nation(s) that stand alone. Let $M$ and $S$ denote the sets of IEA and stand-alone nations, respectively. Let $m \geq 2$ and $s \geq 1$ denote the numbers of IEA members and stand-alone nations, respectively. Note that since $M \cup S=N, m+s=n$. Assuming and interior solution for each $i \in N$, the conditions that characterize the Nash equilibrium for a partial-agreement setting are

$$
\begin{array}{ll}
-c_{r}\left(q_{j}, r_{j}\right)=1, & j \in S, \\
u_{Q}^{j} / u_{x}^{j}=c_{q}\left(q_{j}, r_{j}\right), & j \in S, \\
x_{j}+r_{j}+c\left(q_{j}, r_{j}\right)=w_{j}, & j \in S, \\
-c_{r}\left(q_{k}, r_{k}+\beta R_{-k}\right)=1, & k \in M, \\
u_{Q}^{k} / u_{x}^{k}=c_{q}\left(q_{k}, r_{k}+\beta R_{-k}\right), & k \in M, \\
x_{k}+r_{k}+c\left(q_{k}, r_{k}+\beta R_{-k}\right)=w_{k} . & k \in M,
\end{array}
$$

where $R_{-k}$ denotes the total supply of R\&D in the IEA excluding the R\&D supply of nation $k$. Equations (4.1) - (4.3) are identical to equations (2.1) - (2.3) and equations (4.4) - (4.6) are similar to equations (3.1) - (3.3). 


\section{Self-Enforcing IEAs}

In order to compute and compare equilibrium payoffs, it is necessary to make assumptions about utility and cost functional forms. Henceforth, we assume that $u\left(x_{i}, Q\right)=\left(x_{i} Q\right)^{1 / 2}$ and $c\left(q_{i}, g_{i}\right)=\left(q_{i}-g_{i}\right)^{2} / 2 \quad$ for $\quad q_{i} \geq g_{i} \quad$ and $\quad c=0 \quad$ for $\quad q_{i}<g_{i}$. Note that $c_{q}\left(q_{i}, g_{i}\right)=-c_{r}\left(q_{i}, g_{i}\right)=q_{i}-g_{i}$ and $u_{Q}^{i} / u_{x}^{i}=x_{i} / Q$. In all interior Nash equilibria under NDCs, we obtain $x_{i}=Q, \forall i \in N$. To see this, in the stand-alone setting combine conditions (2.1) and (2.2), in the partial-agreement setting, combine conditions (3.1) and (3.2) and in the globalagreement setting, combine conditions (4.1) and (4.2).

In this section, we carry out the stability analysis under the assumption that all nations are active abatement and R\&D contributors (as assumed in sections 3 and 4). In section 6, we relax this assumption in order to provide an analysis for a more realistic scenario. In this case, some nations are active abatement and $R \& D$ contributors while others are inactive. The active contributors are the wealthier nations.

\subsection{Symmetric Self-Enforcing IEA}

Our benchmark is the symmetric scenario. Let $w_{i}=w, \forall i \in N$. This benchmark enables us to understand the potential (in)stability effects promoted by an unequal world income distribution when we later compare the self-enforcing IEA that emerges under unequal national incomes with the one that emerges under equal national incomes. The conditions that characterize the interior Nash equilibria are as follows:

$$
\begin{array}{lll}
x_{i}=x=Q, & i \in N, & \\
r_{i}=r=w-Q-\frac{1}{2}, & i \in N, & \\
q_{i}=1+r, & i \in N, & \text { if } S=N, \\
q_{k}=1+[1+(m-1) \beta] r, & k \in M, & \text { for } 2 \leq m \leq n, \\
q_{j}=1+r, & j \in S, & \text { for } 2 \leq m<n, \\
Q=\frac{2 w[n+m(m-1) \beta]+n-m(m-1) \beta}{2[n+1+m(m-1) \beta]}, & \text { for } 1 \leq m \leq n .
\end{array}
$$


Conditions (5.1) and (5.2) hold in any interior symmetric Nash equilibrium. Conditions (5.3) hold in the interior Nash equilibrium for the status-quo setting. Conditions (5.4) and (5.5) hold in any interior Nash equilibrium for a partial-agreement coalition structure, where $2 \leq m<n$. Condition (5.4) also holds for the Grand-Coalition structure; namely, for $m=n$. Finally, condition (5.6) provides us with the equilibrium level of the global public good in all interior symmetric Nash equilibria, where $1 \leq m \leq n$. Combining conditions (5.2) and (5.6) yields

$$
r=\frac{2 w-2 n-1}{2[n+1+m(m-1) \beta]}, \quad \text { for } 1 \leq m \leq n .
$$

As condition (5.7) makes it clear, each nation's R\&D contribution decreases in the size of the coalition's membership for $m \geq 2$. The rationale for this is the free-riding effect that occurs with non-cooperative R\&D sharing. Note also that the assumption $2 w>2 n+1$ guarantees that all symmetric Nash equilibria under NDCs are interior. Combining conditions (5.3), (5.4) and (5.5) with condition (5.7), we obtain

$$
\begin{array}{lll}
q_{i}=\frac{2 w+1}{2(n+1)}, & i \in N, & \text { if } S=N, \\
q_{k}=1+\frac{[1+m(m-1) \beta](2 w-2 n-1)}{2[n+1+m(m-1) \beta]}, & k \in M, & \text { for } 2 \leq m \leq n, \\
q_{j}=1+\frac{2 w-2 n-1}{2[n+1+m(m-1) \beta]}, & j \in S, & \text { for } 2 \leq m<n .
\end{array}
$$

Condition (5.8) shows the abatement amount that each nation contributes in the interior Nash equilibrium for the status-quo setting, where $m=1$. Condition (5.9) reveals the abatement quantity provided by each nation that belongs to a partial or to a fully participative agreement. It is straightforward to show that a member's contribution increases as the size of the coalition expands, provided $\beta>0$. This is due to the equilibrium R\&D spillovers produced within the coalition, $m(m-1) \beta r$, which increase in $m$, if $\beta>0$ and $m \geq 2$. Condition (5.10) shows the abatement quantity provided by each nation that does not belong to a partial agreement. Note that this quantity decreases in the size of the coalition.

Since $x_{i}=x=Q, \forall i \in N$, in all interior symmetric Nash equilibria under NDCs, as demonstrated by condition (5.1), the Nash equilibria payoffs can be written as follows, for $1 \leq m \leq n$ : 


$$
u(m)=\frac{2 w[n+m(m-1) \beta]+n-m(m-1) \beta}{2[n+1+m(m-1) \beta]}
$$

Following most of the IEA literature, we utilize the internal- and external-stability criteria to define a stable coalition structure in the symmetric case. For $1 \leq m \leq n$, the conditions are:

(i) A coalition $M$ is internally stable if $u(m) \geq u(m-1)$.

(ii) A coalition $M$ is externally stable if $u(m) \geq u(m+1)$.

As in d'Aspremont et al (1983), the stand-alone coalition structure, where $m=1$, is by default internally stable and the Grand Coalition structure is by default externally stable. The following important result demonstrates that if $\beta>0$ a coalition $M$ is internally stable for $n \geq m \geq 2$ :

Proposition 1. If $w_{i}=w, \forall i \in N, n \geq m \geq 2$ and $\beta \in(0,1]$, we have: $u(m)>u(m-1)$.

Proof. $u(m)>u(m-1)$ if and only if $(m-1) \beta(2 w-2 n-1)>0$. Since $2 w>2 n+1$, $u(m)>u(m-1)$ if and only if $m>1$ and $\beta>0$. Q.E.D.

The important result revealed by Proposition 1 follows from the fact that the global public good increases as the IEA's size expands. Although the abatement contribution of each nation that does not participate in a partial agreement decreases as the size of the coalition expands, as implied by condition (6.10), the abatement contribution of each coalition member increases as the size of the coalition expands, as revealed by condition (6.9). The latter effect is produced by the increase in the coalition's R\&D spillover amount. Therefore, as the size of the coalition expands, the total increase in the members' contribution outweighs the total decrease in the nonmembers' contribution. An immediate implication of Proposition 1 is that a coalition $M$ containing two or more members, except for the Grand Coalition, is externally unstable. Hence, we obtain:

Proposition 2. If $w_{i}=w, \forall i \in N$, and $\beta \in(0,1]$, the stable coalition is the Grand Coalition.

Proposition 2 informs us that the game-theoretic prediction for a world economy that satisfies all modeling assumptions, including symmetry, is that all nations will find it desirable to join a global agreement to share R\&D efforts, even though R\&D contributions are non-cooperative.

\subsection{Asymmetric Self-Enforcing IEA}

Suppose now that $w_{j}>w_{j+1}, j=1, \ldots, n-1$. Let us first determine the conditions that characterize interior Nash equilibria under NDCs. The conditions that characterize an interior Nash equilibrium in the status-quo setting are (6.1) and the following: 


$$
\begin{aligned}
& r_{i}=\frac{2\left[(n+1) w_{i}-W\right]-(2 n+1)}{2(n+1)}, \quad i \in N, \\
& q_{i}=\frac{2\left[(n+1) w_{i}-W\right]+1}{2(n+1)}, \quad i \in N, \\
& R=\frac{2 W-n(2 n+1)}{2(n+1)}, \\
& Q=\frac{2 W+n}{2(n+1)} .
\end{aligned}
$$

Since $x_{i}=Q, \forall i \in N$, in all Nash equilibria, all nations earn the same payoff in any equilibrium, even though they have different income levels. Conditions (6.1) and (6.2) reveal that each nation's R\&D and abatement contributions are increasing functions of its national income level. These conditions imply that $r_{j}>r_{j+1}$ and $q_{j}>q_{j+1}, j=1, \ldots, n-1$. Conditions (6.1) and (6.2) imply that for $j=1, \ldots, n-1$ :

$$
\begin{aligned}
& r_{j}-r_{j+1}=w_{j}-w_{j+1}>0, \\
& q_{j}-q_{j+1}=w_{j}-w_{j+1}>0 .
\end{aligned}
$$

Since $w_{j}>w_{j+1}, j=1, \ldots, n-1$, conditions (6.5) and (6.6) imply that the Nash equilibrium for the status-quo setting under NDCs is interior if and only if $r_{n}>0$. Hence, the necessary and sufficient condition is

$$
w_{n}>\frac{2 W+2 n+1}{2(n+1)} .
$$

Condition (6.7) informs us that the poorest nation's income has to be a sufficiently large fraction of world income. Finally, conditions (6.3) and (6.4) show the R\&D and global public good levels in the Nash equilibrium for the status-quo setting.

The conditions that characterize an interior Nash equilibrium under NDCs in the presence of a coalition $M$ containing $m$ members, where $2 \leq m<n$, are $x_{i}=Q, \forall i \in N$, and the following:

$$
r_{i}=\frac{2\left[(n+1+m(m-1) \beta) w_{i}-\left(W+(m-1) \beta W^{M}\right)\right]-(2 n+1)}{2[n+1+m(m-1) \beta]}, \quad i \in N
$$




$$
\begin{aligned}
& R^{M}=\frac{2\left[(n+1) W^{M}-m W\right]-m(2 n+1)}{2[n+1+m(m-1) \beta]}, \\
& R=\frac{2 W+2(m-1) \beta\left(m W-n W^{M}\right)-n(2 n+1)}{2[n+1+m(m-1) \beta]}, \\
& q_{j}=1+r_{j}, \\
& q_{k}=1+(1-\beta) r_{k}+\beta R^{M}, \\
& Q=\frac{2\left[W+(m-1) \beta W^{M}\right]+n-m(m-1) \beta}{2[n+1+m(m-1) \beta]} .
\end{aligned}
$$

Condition (6.8) implies condition (6.5). Hence, the necessary and sufficient condition for an interior Nash equilibrium under NDCs for a partial agreement, where $2 \leq m<n$, is

$$
w_{n}>\frac{2\left[W+(m-1) \beta W^{M}\right]+2 n+1}{2[n+1+m(m-1) \beta]} .
$$

Note that for $\beta>0$ conditions (6.8) - (6.13) depend on the coalition's income level, $W^{M}$. Hence, given $m$, there are multiple Nash equilibria. The Nash equilibria vary according to the "profile" of the coalition $M$. A coalition's profile is a complete characterization of its members' identities. Equation (6.9) tells us that the total amount of R\&D provided by a coalition $M, R^{M}$, is an increasing function of the coalition's income level. Equation (6.10) shows the total amount of $R \& D$ provided as function of world income, the coalition's income and the coalition's membership size. Equations (6.11) and (6.12) describe the abatement contributions of nonmembers and members, respectively, as functions of $R \& D$ individual contributions (nonmembers) and the weighted average of R\&D individual and group contributions (members). Finally, equation (6.13) shows the global public good as an increasing function of world income and coalition's income. In the presence of unequal incomes, it is not possible a priori to say that the global public good is an increasing function of a coalition's membership size.

The conditions that characterize an interior Nash equilibrium for the Grand Coalition setting are $x_{i}=Q, \forall i \in N$, and the following:

$$
r_{i}=\frac{2\left[w_{i}+(1+(n-1) \beta)\left(n w_{i}-W\right)\right]-(2 n+1)}{2[1+n(1+(n-1) \beta)]}, \quad i \in N
$$




$$
\begin{aligned}
& q_{i}=\frac{2(1-\beta)\left[w_{i}-(1+(n-1) \beta)\left(W-n w_{i}\right)\right]+\beta(2 W-(n-1))+1}{2[1+n(1+(n-1) \beta)]}, \quad i \in N, \\
& R=\frac{2 W-n(2 n+1)}{2[1+n(1+(n-1) \beta)]}, \\
& Q=\frac{2[1+(n-1) \beta] W+n[1-(n-1) \beta]}{2[1+n(1+(n-1) \beta)]} .
\end{aligned}
$$

Equations (6.15) and (6.16) show that nation $i$ 's R\&D and abatement contributions are increasing functions of its income. These equations satisfy conditions (6.5) and (6.6), respectively. Equations (6.17) and (6.18) show the global R\&D and public good levels as functions of global income.

Since $w_{j}>w_{j+1}, j=1, \ldots, n-1$, the necessary and sufficient condition for an interior Nash equilibrium for the Grand Coalition structure under NDCs is

$$
w_{n}>\frac{2 W[1+n(n-1) \beta]+2 n+1}{2[1+n(1+(n-1) \beta)]} .
$$

Now note that condition (6.14) implies condition (6.19) if $m=n$ and condition (6.14) implies condition (6.7) if $m=1$. In addition, since the right-hand side of condition (6.14) is increasing in $W^{M}$, we can summarize the condition for interior Nash equilibria under NDCs as follows:

$$
w_{n}>\frac{2\left[W+(m-1) \beta W^{M^{*}}\right]+2 n+1}{2[n+1+m(m-1) \beta]}, \quad \text { for } \beta \in[0,1], 1 \leq m \leq n,
$$

where $W^{M^{*}} \equiv \sum_{k=1}^{m} w_{k}$ is the maximal income level for a coalition $M$ containing $m \geq 2$ members. The coalition's profile is $M^{*} \equiv\{1, \ldots, m\}$; that is, the coalition formed with the $m$ richest nations.

Condition (6.18) implies that the world income distribution cannot be very unequal in order to guarantee interior Nash equilibria. To see this, consider the following examples. First, suppose that $n=4, w_{1}=100, w_{2}=90, w_{3}=80$ and $w_{4}=70$. In this case, the Nash equilibrium for the status-quo setting $(m=1)$ is interior since $70>[2(340)+9] / 10=68.9$ However, the Nash equilibrium for the setting in which the two richest nations form a coalition is not necessarily interior because $70<1069 / 14 \cong 76.36$. Now, suppose again that $n=4$, but $w_{1}=100, w_{2}=92$, $w_{3}=91$ and $w_{4}=90$. In this case, all Nash equilibria under NDCs are necessarily interior: (i) in 
the status-quo setting, $90>755 / 10=75.5$; (ii) if $m=2,90>1139 / 14 \cong 81.36$; (iii) if $m=3$, $90>1887 / 22 \cong 85.77$; and (iv) if $m=4,90>2993 / 34 \cong 88.03$.

Since $x_{i}=x=Q, \forall i \in N$, in all interior Nash equilibria under NDCs, the equilibrium payoff earned by each nation in every possible setting can be written as follows:

$$
u(m, M)=\frac{2\left[W+(m-1) \beta W^{M}\right]+n-m(m-1) \beta}{2[n+1+m(m-1) \beta]}, \quad \text { for } \beta \in[0,1], 1 \leq m \leq n .
$$

As before, a stable coalition structure requires satisfaction of internal- and external-stability criteria. With heterogeneous players, however, we need to modify the standard internal- and external-stability conditions and also impose an extra condition, which we call "profile stability," in order to characterize a stable coalition structure. Remember that $N=\{1, \ldots, n\}, M \subset N$ contains $m$ members, where $2 \leq m \leq n$, and $S=N / M$. If $m=n, S$ is empty. Let $u(m, M)$ denote the equilibrium payoff earned by any nation in a setting in which there is a coalition $M$ containing $m$ members. We can now define the three stability conditions as follows:

(i) A coalition $M$ is internally stable if

$$
u(m, M) \geq u(m-1, M /\{k\}) \text { for all } k \in M .
$$

(ii) A coalition $M$ is externally stable if

$$
u(m, M) \geq u(m+1, M \cup\{j\}) \text { for all } j \in S .
$$

(iii) A coalition $M$ is profile stable if $\nexists M^{\prime}$ with cardinality $m$ such that

$$
u\left(m, M^{\prime}\right)>u(m, M) \text { for any } k \in M .
$$

Condition (6.22) informs us that a coalition $M$ is internally stable if no member has an incentive to defect. Condition (6.23) states that a coalition $M$ is externally stable if no outside player has an incentive to join. Condition (6.24) tells us that a coalition $M$ is profile stable if no member has an incentive to defect and regroup with a different set of partners in a coalition of similar size. A different set of partners includes replacements ranging from a complete replacement of $m-1$ partners to a replacement of a single partner. Hence, for a fixed size $m$, the profile stable coalition is $M^{*}$. A coalition $M^{*}$ is stable if and only if it is internally and externally stable.

The following proposition states that for $\beta>0$ the Grand Coalition is stable even if the world income distribution is unequal. 
Proposition 3. The Grand Coalition is stable for $w_{j}>w_{j+1}, j=1, \ldots, n-1$, and $\beta \in(0,1]$.

Proof. We only need to show that the Grand Coalition is internally stable for $\beta>0$. For $\beta \in(0,1]$ and $m=n$, the coalition $N$ is internally stable if and only if $u(n, N) \geq u(n, N /\{n\})$ or

$$
\frac{2 W+n+(n-1) \beta(2 W-n)}{2[1+n(1+(n-1) \beta)]} \geq \frac{2 W+n+(n-2) \beta\left(2\left(W-w_{n}\right)-(n-1)\right)}{2[n+1+(n-1)(n-2) \beta]}
$$

After some algebraic manipulations, condition (6.25) simplifies to

$$
(n-2)[n+1+n(n-1) \beta] w_{n}+1-[n+(n-1)(n-2) \beta-3] W-n(2 n-1) \geq 0 .
$$

Combining condition (6.20), evaluated at $m=n$, with the left-hand side of condition (6.26) yields

$$
\begin{aligned}
& (n-2)[n+1+n(n-1) \beta] w_{n}+1-[n+(n-1)(n-2) \beta-3] W-n(2 n-1) \\
& >(n-2)[1+n(n-1) \beta] W-[n+(n-1)(n-2) \beta-3] W+1+\frac{(n-2)(2 n+1)}{2}-n(2 n-1) .
\end{aligned}
$$

The right-hand side of condition (6.27) simplifies to

$$
\left[1+(n-1)^{2}(n-2) \beta\right] W-\frac{n(2 n+1)}{2}>0 .
$$

The left-hand side of condition (6.28) is greater than zero because $W>n w_{n}>n(2 n+1) / 2$. Condition (6.28) implies that

$$
(n-2)[n+1+n(n-1) \beta] w_{n}+1-[n+(n-1)(n-2) \beta-3] W-n(2 n-1)>0 .
$$

This, in turn, proves that $u(n, N)>u(n, N /\{n\})$. Q.E.D.

Proposition 3 reveals that the Grand Coalition may be stable even if the initial income distribution is unequal. This begs the question: is the Grand Coalition the only coalition structure that is stable among all possible coalition structures under NDCs? As we demonstrate below, the answer is affirmative because, as in the symmetric case, all profile-stable coalitions are internally stable. This, in turn, implies that the Grand Coalition is the only coalition that is externally stable. Proposition 4. For $\beta \in(0,1], n \geq m \geq 1$ and $w_{j}>w_{j+1}, j=1, \ldots, n-1$, the Grand Coalition is the only coalition structure that satisfies profile stability, internal stability and external stability.

Proof. Since the stand-alone structure is by default internally stable and we have already shown that the Grand Coalition is internally stable, we need to show that profile-stable coalitions with at least two and at most $n-1$ nations are internally stable. 
Let $W^{M^{*}} \equiv \sum_{i=1}^{m} w_{i}$ and $W^{M^{*} /\{m\}} \equiv \sum_{i=1}^{m-1} w_{i}$, in what follows. For $\beta \in(0,1]$ and $n-1 \geq m \geq 2$, a coalition $M^{*}=\{1, \ldots, m\}$ is internally stable if and only if

$$
\frac{2 W+n+(m-1) \beta\left(2 W^{M^{*}}-m\right)}{2[n+1+m(m-1) \beta]} \geq \frac{2 W+n+(m-2) \beta\left(2 W^{M^{*} /\{m\}}-(m-1)\right)}{2[n+1+(m-1)(m-2) \beta]},
$$

where $M^{*} /\{m\} \equiv\{1, \ldots, m-1\}$. Since $W^{M^{*} /\{m\}}=W^{M^{*}}-w_{m}$, inequality (6.30) implies

$$
(m-2)[n+1+(m-1)(m-2) \beta] w_{m}-(m-1)(2 W+2 n+1)-[(m-1)(m-2) \beta-(n+1)] W^{M^{*}} \geq 0 .
$$

Since $w_{m}>w_{n}$, condition (6.20) implies that for $\beta \in(0,1]$ and $n-1 \geq m \geq 2$,

$$
w_{m}>\frac{2\left[W+(m-1) \beta W^{M^{*}}\right]+2 n+1}{2[n+1+m(m-1) \beta]} .
$$

Given condition (6.32), we can affirm that the left-hand side of condition (6.31) is greater than

$$
(m-2)\left[W+(m-1) \beta W^{M^{*}}\right]+\frac{(m-2)(2 n+1)}{2}-(m-1)(2 W+2 n+1)-[(m-1)(m-2) \beta-(n+1)] W^{M^{*}} .
$$

The expression (6.33) simplifies to

$$
\left(n W^{M^{*}}-m W\right)+\left(W^{M^{*}}-\frac{m(2 n+1)}{2}\right)>0 .
$$

The left-hand side of condition (6.34) is positive because $n W^{M^{*}}>m W$ and $W^{M^{*}} / m>w_{n}>(2 n+1) / 2$. Hence, the left-hand side of condition (6.31) is greater than zero, which implies that $u\left(m, M^{*}\right)>u\left(m-1, M^{*} /\{m\}\right)$ for $\beta \in(0,1]$ and $n-1 \geq m \geq 2$. This, in turn, implies that the Grand Coalition is the only coalition structure that satisfies profile stability, internal stability and external stability. Q.E.D.

Proposition 4 is remarkable. The interior Nash equilibrium for the Grand Coalition is a Strong Nash equilibrium since it is Pareto superior to all other interior Nash equilibria that satisfy profile stability and internal stability. Since a change in the equilibrium payoff corresponds exactly to a change in the equilibrium level of the global public good, the fact that the equilibrium payoff increases with an expansion in the membership size of the profile-stable coalition implies that the 
equilibrium level of the global public good also increases. As we discussed above, an expansion in the membership size promotes opposite reactions on members' and nonmembers' contributions. An expansion in the membership size of the profile-stable coalition increases each current member's R\&D and abatement contributions. However, the expansion decreases each current nonmember's $R \& D$ and abatement contributions. The corresponding change in the equilibrium level of the public good is the net total effect of these countervailing reactions. Since each nation's $R \& D$ and abatement contributions are increasing functions of its income, the overall benefit of keeping member nation $m$ in the coalition turns out to be an increasing function of its income. If this nation's contributions are sufficiently high, it becomes desirable for other coalition members (and nonmembers) to include an extra nation (namely, the richest nation among the remaining stand-alone ones) in the profile-stable coalition. Since all nations earn the same payoff in any interior Nash equilibrium, this extra nation also favors its inclusion in the profile-stable coalition.

The fact that all nations consume the same private good quantity in any interior Nash equilibrium implies that all nations have an equal amount of disposable income for consumption of the private good in any interior Nash equilibrium. This amount of income is equal to the world's average income minus the world's average cost of providing abatement and R\&D. To see this, note that the sum of budget constraints yields $\sum_{i=1}^{n} x_{i}+\frac{n}{2}+R=W$. Since $x_{i}=x=Q, \forall i \in N$, in any interior Nash equilibrium under NDCs, we have $\sum_{i=1}^{n} x_{i}=n x$ and thus $x=w-r-\frac{1}{2}$, where $w=W / n$ and $r=R / n$. Using the budget constraint for nation $i$, we also obtain $w_{i}-r_{i}=w-r$, $\forall i \in N$. Hence, national incomes are redistributed in equilibrium and the mechanism through which this redistribution takes place is the one that underlies the nations' $R \& D$ contributions. The initial income distribution is relevant only with respect to whether the poorest nations have enough income to be active abatement and R\&D contributors. In particular, note that the interior Nash equilibrium for the Grand Coalition structure in this section (where the initial income distribution is unequal) is identical to the interior Nash equilibrium for the Grand Coalition structure of the previous section (where the initial income distribution is perfectly equal), in terms of private and public good consumption levels and the aggregate costs of provision.

Proposition 5. Let $\beta \in(0,1], n \geq m \geq 1$ and $w_{j}>w_{j+1}, j=1, \ldots, n-1$, the interior Nash equilibrium for the Grand Coalition structure yields the same payoff, the same private and public good 
consumption levels and the same aggregate cost levels as the interior Nash equilibrium for the Grand Coalition structure in the symmetric benchmark case.

\subsection{Self-Enforcing IEA with inactive nations}

Having considered IEAs under NDCs with all nations being active in R\&D and abatement provision, we now turn our attention to a more realistic scenario where some nations are active contributors while some others are inactive. For comparison purposes, we assume that the world income level is the same as in section 4 and that there are at least two active nations in all Nash equilibria considered below. In section 4, we show that a nation's R\&D and abatement contributions increase with its income. Hence, the inactive nations in this section are the poorest ones.

Let $A \subset N$ denote the set of active nations. The set of active nations is $A=\{1, \ldots, a\}$, where $n>a \geq 2$. Let $I=\{a+1, \ldots, n\}$ denote the set of inactive nations. National incomes, $\bar{w}_{i}, i \in N$, satisfy $W=\sum_{i=1}^{n} \bar{w}_{i}, \bar{w}_{j}>\bar{w}_{j+1}, j=1, \ldots, n-1, \bar{w}_{h}>w_{h}, h \in A, w_{l}>\bar{w}_{l}, l \in I$. Let $M=M^{*}$ and $A=M^{*} \cup S$, where $S$ is empty if $m=a$. Otherwise, $m+s=a$, with $s \geq 1$. Let $\bar{W}^{A} \equiv \sum_{h \in A} \bar{w}_{h}$ and $\bar{W}^{M^{*}} \equiv \sum_{k \in M^{*}} \bar{W}_{k}$. For $a \geq m \geq 1$, the conditions that characterize the Nash equilibria are $x_{h}=Q, \forall h \in A$, and the following:

$$
\begin{array}{ll}
r_{h}=\frac{2\left[(a+1+m(m-1) \beta) \bar{w}_{h}-\left(\bar{W}^{A}+(m-1) \beta \bar{W}^{M^{*}}\right)\right]-(2 a+1)}{2[a+1+m(m-1) \beta]}, & \\
R^{M^{*}}=\frac{2\left[(a+1) \bar{W}^{M^{*}}-m \bar{W}^{A}\right]-m(2 a+1)}{2[a+1+m(m-1) \beta]}, & \\
R=\frac{2 \bar{W}^{A}+2(m-1) \beta\left(m \bar{W}^{A}-a \bar{W}^{M^{*}}\right)-a(2 a+1)}{2[a+1+m(m-1) \beta]}, & \quad j \in S, \\
q_{j}=1+r_{j}, \quad k \in M^{*}, & \text { for } s \geq 1, \\
q_{k}=1+(1-\beta) r_{k}+\beta R^{M^{*}}, & \text { for } m \geq 2, \\
Q=\frac{2\left[\bar{W}^{A}+m(m-1) \beta \bar{W}^{M^{*}}\right]+a-m(m-1) \beta}{2[a+1+m(m-1) \beta]} . &
\end{array}
$$




$$
\begin{array}{ll}
\bar{w}_{a}>\frac{2\left[\bar{W}^{A}+(m-1) \beta \bar{W}^{M^{*}}\right]+2 a+1}{2[a+1+m(m-1) \beta]}, & \text { for } \beta \in[0,1], \quad 1 \leq m \leq a, \\
\bar{w}_{a+1}<Q \Rightarrow q_{l}=r_{l}=0, \quad x_{l}=w_{l}, & l \in I . \quad \text { for } m \geq 2 .
\end{array}
$$

Conditions $(7.1)-(7.6)$ are similar to conditions (6.8) - (6.13) and condition (7.7) is similar to condition (6.20). Conditions (7.8) hold for the inactive nations.

The following result is straightforward:

Proposition 6. Suppose conditions (7.8) hold. For $\beta \in(0,1], n>a \geq m \geq 1$, and $\bar{w}_{j}>\bar{w}_{j+1}$, $j=1, \ldots, n-1$, coalition $A$ is the only coalition that satisfies profile stability, internal stability and external stability.

Proof. It follows the same reasoning of the proofs for Propositions 3 and 4, replacing $n$ for $a$. Q.E.D.

Since we assume that the world income level is the same as in section 4, the income distribution in this section is more uneven than in section 4. As the welfare of each nation that participates in the IEA rises as active non-participating nations join a self-enforcing agreement, it is desirable to expand the size of the self-enforcing agreement in order to include all active nations. The expansion in the size of the self-enforcing agreement also benefits the inactive nations, since they payoffs are increasing functions of the equilibrium amount of global public good. Hence, the Nash equilibrium for the coalition structure in which all active nations are members of the IEA is a Strong Nash equilibrium.

The reasoning that the expansion in membership size is globally desirable also suggests that active nations may benefit from "transforming" inactive nations into active ones. The total amount of income that would give the inactive nations the same income levels that they have in section 4 is $\sum_{l \in I}\left(w_{l}-\bar{w}_{l}\right)$. The wealthiest nations could pool resources and each provide a proportionally equitable share such as $\left(\bar{w}_{h} / \bar{W}^{A}\right) \sum_{l \in I}\left(w_{l}-\bar{w}_{l}\right), h \in A$, to a global fund (e.g., the new Green Fund) provided that each nation's income donation is feasible (i.e., the nation remains an active abatement and R\&D contributor). ${ }^{3}$ By enabling the inactive nations to become active, the

${ }^{3}$ Alternatively, the wealthiest nations can delegate authority to a global agency to implement international transfers. The global agency, for example, can choose transfer levels in order to maximize the sum of national payoffs. Accordingly, in the second stage of the formation game, the global agency and the nations play a simultaneous noncooperative game. The global agency's choices would imply equal national incomes in any interior Nash equilibrium. 
wealthiest nations would benefit because the resulting stability outcome would be the Grand Coalition. A redistribution of world income in order to provide the poorest nations with sufficient means to become active contributors is globally desirable.

\section{Conclusion}

The Paris agreement has the potential of being a major watershed in history. It has a long-term goal of keeping the increase in global warming well below 2 degrees Celsius. Nonetheless, it is currently known that the nations' intended contributions toward emissions' reductions will lead to a much larger increase in global warming. The Paris Agreement builds on INDCs submitted by most participating nations. Noteworthy aspects of the agreement are improved mechanisms to facilitate technology and monetary transfers from rich to poor participating nations.

In this paper, we carry out the first theoretical analysis in the IEA literature that examines the endogenous formation and stability of an IEA with asymmetric nations under NDCs. The nations are asymmetric because they possess different income levels. The unequal world income distribution matters for the allocation of resources because the payoff functions in our model are nonlinear in private and public good consumption levels. The consumption goods are normal. The unequal world income distribution implies that nations make different carbon abatement and R\&D contributions in the Nash equilibria.

We show that, in the presence of R\&D spillovers within the IEA, the stable coalition under NDCs is the Grand Coalition if all nations are active carbon abatement and R\&D contributors. If some nations are inactive because they lack sufficient income to provide carbon abatement and R\&D, the stable coalition includes all active nations. In such a case, it is beneficial for the wealthier, active, nations to transfer income to inactive nations to enable the latter to become active contributors.

\section{References}

Barrett, S., 1994, Self-enforcing international environmental agreements, Oxford Economic Papers 46, 878-894.

Barrett, S., 2006, Climate treaties and "breakthrough" technologies, American Economic Review 96, 22-25.

Barrett, S., 2009, The coming global climate - technology revolution, Journal of Economic Perspectives 23, 53-75. 
Biancardi, M., Villani, G., 2010, international environmental agreements with asymmetric countries, Computational Economics 36, 69-92.

Carraro, C., Siniscalco, D., 1991, Strategies for international protection of the environment, Discussion Paper 568, Centre for Economic Policy Research, London.

Carraro, C., Siniscalco, D., 1993, Strategies for international protection of the environment, Journal of Public Economics 52, 309-328.

d'Aspremont, C., Jacquemin, J., Gadszeweiz, J., Weimark, J.A., 1983, On the stability of collusive price leadership, Canadian Journal of Economics 16, 17-25.

Diamantoudi, E., Sartzetakis, E., 2006, Stable international environmental agreements: an analytical approach, Journal of Public Economic Theory 8, 247-263.

Eichner, T., Pethig, R., 2013, Self-enforcing environmental agreements and international trade, Journal of Public Economics 102, 37-50.

Eichner, T., Pethig, R., 2014, Self-enforcing environmental agreements and capital mobility, Regional Science and Urban Economics 48, 120-132.

El-Sayed, A., Rubio, S.J., 2014, Sharing R\&D investments in cleaner technologies to mitigate climate change, Resource and Energy Economics 38, 168-180.

Fuentes-Albero, C., Rubio, S.J., 2010, Can international environmental cooperation be bought?, European Journal of Operational Research 202, 255-264.

Hoel, M., 1992, International environmental conventions: the case of uniform reductions of emissions, Environmental and Resource Economics 2, 141-159.

Katz, M.L., 1986, An analysis of cooperative research and development, Rand Journal of Economics 17, 527-543.

Kolstad, C., 2007, Systematic uncertainty in self-enforcing international environmental agreements, Journal of Environmental Economics and Management 53, 68-78.

McGinty, M., 2007, International environmental agreements among asymmetric nations, Oxford Economic Papers 59, 45-62.

Nordhaus, W., 2015, Climate-clubs: overcoming free-riding in international climate policy, American Economic Review 105, 1339-1370.

Osmani, D., Tol, R.S.J., 2010, The case of two self-enforcing international agreements for environmental protection with asymmetric countries, Computational Economics 36, 93-119. 
Pavlova, Y., de Zeeuw, A., 2013, Asymmetries in international environmental agreements, Environment and Development Economics 18, 51-68.

Rūbbelke, D.T.G., Finus, M., Public good provision and ancillary benefits: the case of environmental agreements, Environmental and Resources Economics 56, 221-226.

Rubio, S.J., Casino, B., 2005, Self-enforcing environmental agreements with a stock pollutant, Spanish Economic Review 7, 89-109.

Rubio, S.J., Ulph, A., 2006, Self-enforcing international environmental agreements revisited, Oxford Economic Papers 58, 233-263.

Rubio, S.J., Ulph, A., 2006, Self-enforcing agreements and international trade in greenhouse emission rights, Oxford Economic Papers 58, 233-263.

Silva, E.C.D., Yamaguchi, C., 2015, Overlapping international green R\&D agreements, unpublished paper.

Silva, E.C.D., Zhu, X., 2015, Overlapping international environmental agreements, forthcoming in Strategic Behavior and the Environment. 